\title{
Making COPD Self-Management Education Work
}

The chronic nature of COPD requires that individuals manage their changing condition over time to optimize their quality of life, reduce exacerbations, and limit dyspnea. ${ }^{1}$ This month's issue of ResPiRATORy CARE explores 2 broad topics of COPD self-management education from the perspective of patients ${ }^{2}$ and that of pulmonologists and pulmonary fellows. ${ }^{3}$ These topics address how to treat COPD and prevent exacerbations as well as the use and preferences of inhaled medication devices.

In the survey by Dhand et al, ${ }^{2}$ the majority of respondents who had COPD felt they understood their condition. This is consistent with the confidence that most pulmonologists and fellows felt about their own COPD medication knowledge and how to prevent exacerbations in the survey by Braman et al. ${ }^{3}$ However, when individuals with COPD were asked about symptoms and causes of COPD, their knowledge was correct only $50 \%$ of the time. Approximately one third of respondents were knowledgeable about medications to treat COPD and about COPD exacerbation prevention strategies. ${ }^{2}$ These knowledge gaps highlight the complex nature of patient education and the need for repetition. It also reinforces the need for teach back as a method of confirming what patients actually understand.

The second broad topic addressed inhaled treatments for COPD. Small-volume nebulizers (SVNs) have been used to aerosolize liquid medication for a long time. More portable options such as pressurized metered-dose inhalers (pMDIs), dry powder inhalers (DPIs), and soft mist inhalers followed. This growth in options created more decisions for delivering inhaled medication. The Global Initiative for Chronic Obstructive Lung Disease (GOLD) 2017 guidelines recommend selecting an inhalation device based on availability, cost, provider, and patient. Engaging patients as partners in their care is key. ${ }^{4}$ Patients may be prescribed a medication in the clinic only to find that it is not covered by their insurance. Frequent inhalation device changes due to insur-

The author has disclosed no conflicts of interest.

Correspondence: Ellen A Becker PhD RRT RRT-NPS RPFT AE-C FAARC, Department of Cardiopulmonary Sciences, Rush University, 600 S. Paulina Street, Chicago, IL 60612. E-mail: ellen_becker@ rush.edu.

DOI: $10.4187 /$ respcare.06389 ance switches create opportunities for potential misuse and suboptimal care. ${ }^{5}$ Specific patient-related topics related to misuse include technical considerations such as the ability to read dose counters, load medications into devices, assemble devices, inhale properly to obtain an appropriate dose, activate the device to release the medication, and keep devices clean for future use. Of equal importance is patient preference. Individuals are more likely to use devices that they prefer. ${ }^{6}$

See the Original Study on Page 833 and 840

The survey of individuals with COPD solicited the types of inhaled devices respondents used and detailed information about their beliefs regarding SVNs. Opinions about preference for SVNs over more portable devices were almost equally split. Approximately half of the survey respondents preferred the SVN over a pMDI and a DPI (54\%), while $46 \%$ disagreed. $^{2}$ The companion survey of pulmonologists and fellows ${ }^{3}$ demonstrated that physicians were less confident in how to use and clean/maintain inhalation devices than they were about COPD medications and management, preventing exacerbations, and treatment devices. The investigators delved further into physician knowledge about who should use SVNs and how to clean or maintain them, and they found that less than one third of respondents felt knowledgeable in these areas. The survey explored more detailed questions regarding the SVN than regarding the pMDI, the DPI, and the soft mist inhaler. Although this survey explored the different modified Medical Research Council dyspnea levels at which pulmonologists and pulmonary fellows prescribed SVNs, evidence does not support that SVNs are superior to other inhaler devices, provided that patients can use them appropriately. 4,7

The number of people who correctly use inhalers improved when providers and patients received adequate education. ${ }^{8}$ Inhaler assessments need to be conducted by a skilled individual ${ }^{4,8}$ and reassessed at regular intervals. ${ }^{4,6,8}$ The challenge arises when health care providers are not adequately trained and there is insufficient time for education. ${ }^{8}$ One third of respondents with COPD indicated a lack of time for discussing their condition, and more than half of participants did not recall receiving training on their devices on their first visit. ${ }^{2}$ Both training and time 
appear to contribute to the problem. The American College of Chest Physicians and Canadian Thoracic Society Guideline on the Prevention of Acute Exacerbations of COPD highlights that a specially trained staff for education and case management is needed to supervise educational interventions. ${ }^{9}$

The findings from the 2 studies in this issue imply that the educational demands for COPD education may not simply fit into routine office visits or hospitalizations. A systematic review of randomized, controlled trials addressing inhaler education found that slightly more than half of the included studies embedded inhaler education in another intervention. The average number of sessions from their study was 2.6 , and mean duration was $30 \mathrm{~min} .{ }^{5} \mathrm{Im}$ provements in inhaler use occurred independently of the duration of intervention, individual versus group intervention, type of intervention (video vs demonstration), or whether the intervention took place within a larger teaching session. In addition, follow-up within 5 months contributed to improvements. Results were consistent for both asthma and COPD. None of these studies looked at SVN use.

An even larger challenge emerges when considering that the medical provider information from this month's issue presented data from pulmonologists and pulmonary fellows. ${ }^{3}$ The majority of individuals with COPD receive care from primary care providers. A study that evaluated primary care providers' knowledge of COPD practices in an urban area found that $<60 \%$ adhered to most of the GOLD guidelines. Less than half of the respondents knew that the GOLD guidelines existed, even though they were published 10 years earlier. Not all who were aware of the guidelines read them. ${ }^{10}$ Thus, the actual medical provider knowledge of COPD management across practices is likely much lower than that reported in this month's issue.

Given the time commitment for self-management education, successful programs will need to take a broader COPD team effort and cross boundaries of traditional patient education settings. Respiratory therapists, for example, have the knowledge and skills to provide COPD management, and their effectiveness has been demonstrated, ${ }^{11,12}$ as do others from the disciplines of pharmacy and nursing. Although evidence from telehealth settings are not conclusive, ${ }^{9,13}$ other creative models for providing this interprofessional education across settings are available. ${ }^{14}$ Future work in self-management education needs to grapple with how to effectively reinforce key educational messages when delivered through multiple providers, identify the messages that affect patient outcomes the most, and identify how to integrate this education into the routine workflow within the time constraints and personnel available.
Ellen A Becker PhD RRT RRT-NPS RPFT AE-C

FAARC

Department of Cardiopulmonary Sciences

Rush University

Chicago, Illinois

\section{REFERENCES}

1. Zwerink M, Brusse-Keizer M, van der Valk PD, Zielhuis GA, Monninkhof EM, van der Palen J, et al. Self-management for patients with chronic obstructive pulmonary disease. Cochrane Database Syst Rev 2014;(3):CD002990.

2. Dhand R, Mahler DA, Carlin B, Hanania N, Ohar J, Pinto-Plata V, et al. Results of a patient survey regarding COPD knowledge, treatment experiences, and practices with inhalation devices. Respir Care 2018;63(7):833-839.

3. Braman SS, Carlin BW, Hanania NA, Mahler DA, Ohar JA, PintoPlata V, et al. Results of a pulmonologist survey regarding knowledge and practices with inhalation devices for COPD. Respir Care 2018;63(7):840-848.

4. Global Initiative for Chronic Obstructive Lung Disease. Global Strategy for the Diagnosis, Management and Prevention of COPD, 2017. Available at: http://goldcopd.org. Accessed May 20, 2018.

5. Klijn SL, Hiligsmann M, Evers SMAA, Roman-Rodriguez M, van der Molen T, van Boven JFM. Effectiveness and success factors of educational inhaler technique interventions in asthma and COPD patients: a systematic review. NPJ Prim Care Respir Med 2017;27(1):24.

6. Gregory KL, Wilken L, Hart MK. Pulmonary disease aerosol delivery devices: a guide for physicians, nurses, pharmacists, and other health care professionals, 3rd edition. American Association for Respiratory Care. Available at: http://www.aarc.org/wp-content/uploads/ 2018/01/aerosol-guide-for-hcp-3rd.pdf. Accessed May 20, 2018.

7. Dolovich MB, Ahrens RC, Hess DR, Anderson P, Dhand R, Rau JL, et al. Device selection and outcomes of aerosol therapy: evidence-based guidelines: American College of Chest Physicians/American College of Asthma, Allergy, and Immunology. Chest 2005;127(1):335-371.

8. Riley J, Kruger P. Optimising inhaler technique in chronic obstructive pulmonary disease: a complex issue. Br J Nurs 2017;26(7):391397.

9. Criner GJ, Bourbeau J, Diekemper RL, Ouellette DR, Goodridge D, Hernandez $\mathrm{P}$, et al. Prevention of acute exacerbations of COPD: American College of Chest Physicians and Canadian Thoracic Society Guideline. Chest 2015;147(4):894-942.

10. Perez X, Wisnivesky JP, Lurslurchachai L, Kleinman LC, Kronish IM. Barriers to adherence to COPD guidelines among primary care providers. Respir Med 2012;106(3):374-381.

11. Silver PC, Kollef MH, Clinkscale D, Watts P, Kidder R, Eads B, et al. A respiratory therapist disease management program for subjects hospitalized with COPD. Respir Care 2017;62(1):1-9.

12. Rice KL, Dewan N, Bloomfield HE, Grill J, Schult TM, Nelson DB, et al. Disease management program for chronic obstructive pulmonary disease: a randomized controlled trial. Am J Respir Crit Care Med 2010;182(7):890-896.

13. Hanlon P, Daines L, Campbell C, McKinstry B, Weller D, Pinnock $\mathrm{H}$. Telehealth interventions to support self-management of long-term conditions: a systematic metareview of diabetes, heart failure, asthma, chronic obstructive pulmonary disease, and cancer. J Med Internet Res 2017;19(5):e172.

14. Pelland K, Youssef R, Calandra K, Cellar J, Thiesen J, Gardner R. Results from a community-wide pilot program to standardize COPD education for patients across healthcare settings in Rhode Island. $\mathrm{R}$ I Med J (2013) 2017;100(7):18-21. 